\title{
Implication of peroxisomes and mitochondria in the halophyte Cakile maritima tolerance to salinity stress
}

\author{
N. BEN AMOR ${ }^{1 *}$, A. JIMENEZ ${ }^{2}$, M. BOUDABBOUS ${ }^{3}$, F. SEVILLA $^{2}$, and C. ABDELLY ${ }^{1}$ \\ Laboratory of Plant Extremophiles, Biotechnology Center, 2050 Borj Cédria, Tunisia ${ }^{1}$ \\ Department of Stress Biology and Plant Pathology, CEBAS-CSIC, 30100 Murcia, Spain ${ }^{2}$ \\ Laboratory of Molecular Biotechnology of Eukaryotes, CBS, 3018 Sfax, Tunisia ${ }^{3}$
}

\begin{abstract}
The role of mitochondria and peroxisomes in the tolerance of the halophyte Cakile martima to salt stress was studied. The plants were subjected to 0,100 , and $200 \mathrm{mM} \mathrm{NaCl}$ for 5 weeks. The evaluation of oxidative stress according to the content of malondialdehyde (MDA), carbonyl $\left(\mathrm{CO}^{-}\right)$proteins, $\mathrm{O}_{2}^{-}$, and $\mathrm{H}_{2} \mathrm{O}_{2}$, and the activities of several antioxidant enzymes, such as superoxide dismutase, peroxidase, and enzymes of the ascorbate-glutathione cycle were determined in two purified organelles, mitochondria and peroxisomes. The intact organelles were purified by centrifugation in Percoll density gradients. Results show that the content of MDA and $\mathrm{CO}^{-}$proteins was higher in mitochondria than in peroxisomes under the salt stress. The antioxidant enzymes showed higher activities in peroxisomes than in mitochondria under different $\mathrm{NaCl}$ concentrations. These activities were highest at $100 \mathrm{mM} \mathrm{NaCl}$. Our results suggest that the ascorbate glutathione cycle in peroxisomes plays a key role in the tolerance of Cakile maritima to salinity.
\end{abstract}

Additional key words: ascorbate-glutathione cycle, carbonyl proteins, $\mathrm{H}_{2} \mathrm{O}_{2}$, malondialdehyde, $\mathrm{NaCl}_{2} \mathrm{O}_{2}^{-}$, peroxidase, superoxide dismutase.

\section{Introduction}

Sodium chloride is the most abundant salt in salinityaffected land. Salt stress is a major impairment to agricultural production that limits plant growth and yield. It is clear from the growing body of experimental evidence that salt stress affects the integrity of cellular membranes, the activities of enzymes, as well as the photosynthetic apparatus (Serrano et al. 1999). An important cause of this damage is the production of reactive oxygen species (ROS) (Smirnoff 1993). Chloroplasts, mitochondria, and peroxisomes are intracellular generators of ROS (Jimènez et al. 1998, Foyer and Noctor 2003, Del Río et al. 2006, Karkonen and Kuchitsu 2015). When ROS production is high, they can cause a substantial cellular damage (Sairam and Srivastava 2002, Ashraf 2009). The balance between

ROS production and the activities of these ROSremoving systems determines the degree of possible oxidative stress. Thus, it determines to what extent signaling and/or damage will occur (Demidchik 2015). The question that arises here is how can a plant control and speed up the rate of ROS production and ROS scavenging when it is exposed to salinity. The amount of ROS depends on the rate of generation, reaction with other metabolites, such as proteins, lipids, and nucleic acids, the rate of their degradation, and the rate of their scavenging/neutralizing by enzymatic and/or nonenzymatic antioxidants (Mittler 2002, Ben Amor et al. 2005, Ashraf 2009). The plant cell and its organelles peroxisomes, chloroplasts, and mitochondria contain multiple enzymes or enzymes systems responsible for

Submitted 13 September 2017, last revision 27 August 2018, accepted 17 September 2018.

Abbreviations: APX - ascorbate peroxidase; BSA - bovine serum albumin; CAT - catalase; DHAR - dehydroascorbate reductase; GR - glutathione reductase; HPR - hydroxypyruvate reductase; MDA - malondialdehyde; MDHAR - monodehydroascorbate reductase; Mes - 2-(N-morpholino)ethanesulfonic acid; MOPS - 3-(N-morpholino)propanesulfonic acid; POD - non-specific peroxidase; PMSF - phenylmethylsulfonyl fluoride; ROS - reactive oxygen species, SOD - superoxide dismutase, Suc - sucrose.

Acknowledgments: This study was supported by the Tunisian Scientific Ministry of Higher Education and Research and the Spanish Agency of International cooperation for the Development (AECID). We are deeply grateful to Prof. Hamadi Fetoui (Life Sciences department, Faculty of Science of Sfax, Tunisia) for improving the manuscript.

* Corresponding author; fax: (+21) 674246347, e-mail: nadeur33@yahoo.fr 
removing ROS (Asada 2000, Mittler 2002).

The components of the ascorbate glutathione cycle (the Halliwell-Asada cycle) represent a highly effective detoxification mechanism against $\mathrm{H}_{2} \mathrm{O}_{2}$ (Foyer et al. 1997). This cycle functions in most of the subcellular compartments of both photosynthetic and nonphotosynthetic tissues (Del Río et al. 2002, Sevilla 2015).

Halophytes are known for their ability to quench ROS since they have a powerful antioxidant system (Ben Amor et al. 2005, 2006, Lokhande and Suprasanna 2012). However, only few information concerning $\mathrm{NaCl}$-induced mitochondrial and peroxisomal ROS scavenging systems in detail do exist.

Cakile maritima (sea rocket) is an annual halophyte diploid species characterized by a $\mathrm{C}_{3}$ pathway of photosynthesis. It has a short life cycle and produces a large number of seeds (10000 seeds per plant) (Debez et al. 2012). This species is found frequently along the Tunisian seashore (Debez et al. 2004). In addition to its ecological interest for dune and saline soil stabilization, C. maritima has a potential economic significance as its seeds contain appreciable amounts of oil (40\% on dry mass basis) (Zarrouk et al. 2003). Ben Amor et al. (2006) showed that the relative salt tolerance of Cakile maritima is associated with high antioxidant enzyme activities. However, the implication of cell organelles for eliminating oxidative stress as well as their roles in salt tolerance is not known yet. Thus, the aim of this study was to investigate the relationship between response of Cakile maritima to $\mathrm{NaCl}$-induced oxidative stress and its salinity tolerance and to examine the roles of mitochondria and peroxisomes in antioxidant defense.

\section{Materials and methods}

Plants and culture conditions: The mature seeds of Cakile maritima Scop. were collected from sandy beaches in Djerba, an island which is close to the Mediterranean seashore, $520 \mathrm{~km}$ south of Tunis. Seeds were sown in pots (4 seeds per pot) filled with $3 \mathrm{~kg}$ of inert sand and irrigated with distilled water until germination. After 3 weeks, seedlings were watered daily with a Hewitt (1966) nutrient solution ( $\mathrm{pH} 7.3$, electric conductivity, EC $2.7 \mathrm{mS} \mathrm{cm} \mathrm{cm}^{-1}$ ). Five-week-old seedlings were subjected to $0,100,200 \mathrm{mM} \mathrm{NaCl}$ for 5 weeks (the salt concentrations were daily stepwise increased with $50 \mathrm{mM} \mathrm{NaCl}$ ). The experiment was conducted in a growth room under day/night temperatures of $25 / 15^{\circ} \mathrm{C}$ and realtive humidities of $70 / 90 \%$, a $16-\mathrm{h}$ photoperiod, and photosynthetic active radiation of $440 \mu \mathrm{mol} \mathrm{m}^{-2} \mathrm{~s}^{-1}$.

Purification of cell organelles: Leaf mitochondria and peroxisomes were isolated by differential and densitygradient centrifugation as described by Jiménez et al. (1997) but with some minor modifications. All operations were realized at $0{ }^{\circ} \mathrm{C}$. Leaves $(50 \mathrm{~g})$ were chopped in $200 \mathrm{~cm}^{3}$ of extraction medium ( $\mathrm{pH}$ 7.3) containing $30 \mathrm{mM}$ 3-(N-morpholino)propanesulfonic acid (Mops), $1 \mathrm{mM}$ EDTA, $0.35 \mathrm{M}$ mannitol, $0.2 \%(\mathrm{~m} / \mathrm{v})$ bovine serum albumine (BSA), and $0.1 \mathrm{M}$ phenyl-methylsulfonyl fluoride (PMSF). The homogenate was filtered through two layers of Miracloth. The chloroplasts were sedimented by centrifugation of the homogenate at $2200 \mathrm{~g}$ for $5 \mathrm{~min}$. The supernatant was centrifuged at $12000 \mathrm{~g}$ for $10 \mathrm{~min}$, and the obtained supernatant was considered as the cytosolic fraction. The pellet was resuspended in a wash medium [10 mM Mops ( $\mathrm{pH} 7.2$ ), 0.35 M mannitol, $1 \mathrm{mM}$ EDTA, and $0.1 \%(\mathrm{~m} / \mathrm{v}) \mathrm{BSA}]$ and centrifuged at $2200 \mathrm{~g}$ for $5 \mathrm{~min}$. In the supernatant, mitochondria and peroxisomes were finally pelleted at $12000 \mathrm{~g}$ for $15 \mathrm{~min}$. The total enzyme activity in the organelle fraction was determined in the pellet that was resuspended in a small volume of the wash medium.

The separation of mitochondria and peroxisomes was achieved by a self-generated Percoll gradient. In fact, $2.5 \mathrm{~cm}^{3}$ of the suspension of the " $12000 \mathrm{~g}$ pellet" in the wash medium was layered on a discontinuous gradient composed of 4 different concentrations of Percoll from the bottom to the top $(53,38,20$, and $15 \%, \mathrm{v} / \mathrm{v})$, respectively. Then, centrifugation at $12000 \mathrm{~g}$ for $35 \mathrm{~min}$ was realized. We obtained purified peroxisomes and a fraction enriched with mitochondria. The intact peroxisomes were obtained definitively after a wash [10 mM Mops ( $\mathrm{pH} 7.2$ ), 0.35 M mannitol, and $1 \mathrm{mM}$ EDTA] and a centrifugation at $12500 \mathrm{~g}$ for $15 \mathrm{~min}$. This step was repeated four times, and the pellet was delicately resuspended in a small volume of the same medium. On the other hand, $3 \mathrm{~cm}^{3}$ of the extraction medium without PMSF was added in the fraction enriched with mitochondria, a centrifugation at $12500 \mathrm{~g}$ for $15 \mathrm{~min}$ was made, $10 \mathrm{~cm}^{3}$ of the wash medium was added to the pellet, and the same centrifugation as before was realized. The pellet was resuspended in $2.5 \mathrm{~cm}^{3}$ of the wash medium and fractionated on a gradient composed at the bottom of $13 \mathrm{~cm}^{3}$ of $30 \%(\mathrm{v} / \mathrm{v})$ Percoll in $0.42 \mathrm{M}$ sucrose, $13.9 \mathrm{mM}$ Mops ( $\mathrm{pH} 7.2)$, and $0.14 \%(\mathrm{~m} / \mathrm{v})$ BSA. The top contained $18.5 \mathrm{~cm}^{3}$ of $28 \%$ (v/v) Percoll in 0.41 M mannitol, $13.9 \mathrm{mM}$ Mops ( $\mathrm{pH} 7.2$ ), and $0.14 \%$ BSA. The gradients were centrifuged at $41400 \mathrm{~g}$ for $35 \mathrm{~min}$. The purified mitochondria were recuperated. The intact mitochondria were diluted 10 times with the wash medium without BSA and spun down at $12000 \mathrm{~g} 4$ times for $35 \mathrm{~min}$. Finally, the pellet was carefully resuspended in a small volume of the same medium. In the studies of ascorbate peroxidase (APX) activity, an independent organelle isolation was used adding $20 \mathrm{mM}$ sodium ascorbate to the extraction medium, and all of the other 
solutions contained $2 \mathrm{mM}$ ascorbate to prevent possible inactivation of APX.

Lipid peroxidation assay: The extent of lipid peroxidation in the different cell compartments was estimated by determining the concentrations of substances reacting with thiobarbituric acid (Buege and Aust 1972).

Protein carbonyl content assay: Carbonyl content was assayed by reaction with 2.4-dinitrophenylhydrazine as described by Levine et al. (1990) with some modifications. The homogenate [a mixture of $0.1 \mathrm{~cm}^{3}$ of the mitochondrial suspension or peroxisomal suspension and a protease inhibitor $(0.2 \mu \mathrm{g}$ each of leupeptin and aprotinin)] reacted with $0.5 \mathrm{~cm}^{3}$ of $10 \mathrm{mM}$ 2.4-dinitrophenylhydrasine or $2 \mathrm{M} \mathrm{HCl}$ (control). The samples were then incubated at room temperature for $1 \mathrm{~h}$ with vortexing every $10 \mathrm{~min}$, then the proteins were precipitated with trichoracetic acid. The tubes were centrifuged at $11000 \mathrm{~g}$ for $3 \mathrm{~min}$, and the supernatant was discarded. The pellet was washed with $1 \mathrm{~cm}^{3}$ of an ethanol and ethyl acetate $(1: 1)$ mixture 3 times. The final protein pellets were dissolved in $0.5 \mathrm{~cm}^{3}$ of guanidine $(6 \mathrm{M}$, with $20 \mathrm{mM}$ potassium phosphate adjusted to $\mathrm{pH} 2.3$ with trifluoroacetic acid) at $37^{\circ} \mathrm{C}$ for $1 \mathrm{~min}$. The solution was centrifuged at $11000 \mathrm{~g}$ for 3 min. Hydrochloric acid ( $2 \mathrm{M}$ ) was added into the supernatant instead of 2.4-dinitrophenylhydrazine as a blank. Absorbance was determined at $360 \mathrm{~nm}$. The carbonyl content was calculated using a coefficient of absorbance $(\varepsilon)$ of hydrazine $\left(22000 \mathrm{M}^{-1} \mathrm{~cm}^{-1}\right)$.

Determination of $\mathrm{H}_{2} \mathrm{O}_{2}$ content: The $\mathrm{H}_{2} \mathrm{O}_{2}$ content was determined by peroxidase-coupled assay using 4-aminoantipyrine and phenol as donor substrates (Frew et al. 1983). Briefly, $0.15 \mathrm{~cm}^{3}$ of each organelle fraction was mixed with $25 \mathrm{mM}$ phenol, $5 \mathrm{mM}$ 4-amino-antipyrine, $0.1 \mathrm{M}$ potassium phosphate buffer ( $\mathrm{pH}$ 6.9), $0.02 \mu \mathrm{M}$ peroxidase, and $2.5 \mu \mathrm{M} \mathrm{H}_{2} \mathrm{O}_{2}$. Quinoneimine formation was measured at $505 \mathrm{~nm}$.

Superoxide radical content in purified submitochondrial particles was determined according to the method of Boveris (1984) and following the superoxide dismutaseinhibitable oxidation of epinephrine using NADH and succinate as respiratory substrates. The amount of $\mathrm{O}_{2}$ radicals produced was calculated using $\varepsilon$ of $4.0 \mathrm{mM}^{-1} \mathrm{~cm}^{-1}$ for epinephrine.

Enzyme assays: The activities of all enzymes were assayed in organelle samples diluted 2- to 8-fold with $50 \mathrm{mM}$ potassium phosphate buffer $(\mathrm{pH}$ 7.8) containing $0.1 \%(\mathrm{v} / \mathrm{v})$ Triton $X-100$. Superoxide dismutase (EC 1.15.1.1) activity was assayed by the ferricytochrome $C$ method using xanthine/xanthine oxidase as a source of superoxide radicals (McCord and Fridovich 1969). A reaction mixture consisted of $50 \mathrm{mM}$ potassium phosphate buffer, $1 \mathrm{mM}$ cytochrome $c, 1 \mathrm{mM}$ xanthine, 0.04 units of xanthine oxidase, and the crude enzyme extract. One unit of SOD was defined as the amount of SOD required to inhibit the rate of cytochrome $c$ oxidation by $50 \%$.

Catalase (CAT; EC 1.11.1.6) activity was measured spectrophotometrically according to the method of Aebi (1984) by monitoring a decline in absorbance at $240 \mathrm{~nm}$ as $\mathrm{H}_{2} \mathrm{O}_{2}$ was consumed $\left(\varepsilon=39.4 \mathrm{mM}^{-1} \mathrm{~cm}^{-1}\right)$. A reaction mixture contained $50 \mathrm{mM}$ potassium phosphate buffer, $10 \mathrm{mM} \mathrm{H}_{2} \mathrm{O}_{2}$, and the crude enzyme extract.

Peroxidase (POD; EC 1.11.1.7) activity was determined spectrophotometrically by measuring the oxidation of $o$-dianisidine (3, 3'-dimethoxybenzidine) at $460 \mathrm{~nm}$ (Ranieri et al. 2000). One unit of the enzyme activity corresponds to an amount of oxidized dianisidine per minute.

Ascorbate peroxidase (APX; EC 1.11.1.11) activity was measured spectrophotometrically according to Jimènez et al. (1997) by following a decline in absorbance at $290 \mathrm{~nm}$ as ascorbate was oxidized $\left(\varepsilon=2.8 \mathrm{mM}^{-1} \mathrm{~cm}^{-1}\right)$. The oxidation rate of ascorbate was estimated between 1 and $60 \mathrm{~s}$ after starting the reaction with the addition of $\mathrm{H}_{2} \mathrm{O}_{2}$.

Monodehydroascorbate reductase (MDHAR; EC 1.6.5.4) activity was assayed at $25^{\circ} \mathrm{C}$ by monitoring a decrease in the absorbance at $340 \mathrm{~nm}$ (Arrigoni et al. 1981). Monodehydroascorbate was generated by the ascorbate/ascorbate oxidase system. A reaction mixture contained $100 \mathrm{mM}$ potassium phosphate buffer ( $\mathrm{pH} 7.0)$, $1 \mathrm{mM}$ ascorbate, $0.2 \mathrm{mM} \mathrm{NADH}, 2 \mathrm{U}$ of ascorbate oxidase from Cucurbita sp. (Sigma, St. Louis, USA), and the crude enzyme extract.

Dehydroascorbate reductase (DHAR; EC 1.8.5.1) activity was assayed following an increase in absorbance at $265 \mathrm{~nm}$ (Dalton et al. 1993) due to reduced glutathione dependent production of ascorbate and using the $\mathrm{N}_{2}$-bubbled buffer. A reaction mixture $\left(1.0 \mathrm{~cm}^{3}\right)$ contained $100 \mathrm{mM}$ potassium phosphate buffer, $4 \mathrm{mM}$ dehydroascorbate, $50 \mathrm{mM}$ reduced glutathione, and the crude enzyme extract. The reaction rate was corrected for a non-enzymatic reduction of dehydroascorbate by reduced glutathione. A factor of 0.98 to account for a small contribution to the absorbance by oxidized glutathione was used.

Total glutathione reductase (GR; EC 1.6.4.2) activity was determined by following the rate of NADPH oxidation as measured by a decrease in absorbance at $340 \mathrm{~nm}$ (Edwards et al. 1990). Reactions were carried out in $100 \mathrm{mM}$ Hepes ( $\mathrm{pH} 7.8$ ) containing $4 \mathrm{mM}$ NADPH, $3 \mathrm{mM} \mathrm{MgCl}_{2}, 1 \mathrm{mM}$ EDTANa 2 , and $0.62 \mathrm{mM}$ oxidized glutathione. The reaction rate was corrected for a small and non-enzymatic oxidation of NADPH by reduced glutathione.

D-glucose 6-phosphate: NADP 1-oxidoreductase (Glc-6-P; EC 1.1.1.49) was assayed spectrophoto- 
metrically monitoring NADP reduction at $340 \mathrm{~nm}$. A reaction mixture contained $50 \mathrm{mM}$ Hepes-NaOH (pH 7.2), $5 \mathrm{mM} \mathrm{MgCl}_{2}$, and $1 \mathrm{mM}$ NADP, and was initiated with $1 \mathrm{mM}$ glucose-6-phosphate (Doehlert et al. 1988).

Cytochrome $c$ oxidase (EC 1.9.3.1) activity was based on cytochrome $c$ oxidation and was followed at $550 \mathrm{~nm}$ (Hernández et al. 1993). A reaction mixture consisted of $100 \mathrm{mM}$ potassium phosphate buffer, $0.4 \mathrm{mM}$ sodium hydrosulfate, and $24 \mu \mathrm{M}$ cytochrome $c$. Fumarase (EC 4.2.1.2) activity was estimated by the measurement of the increase of absorbance at $240 \mathrm{~nm}$ (Bergmeyer et al. 1974) in consequence to the formation of malate from fumarate. One unit corresponds to conversion of $1.0 \mu \mathrm{mol}$ of L-malate to fumarate per minute at $\mathrm{pH} 7.6$ and $25^{\circ} \mathrm{C}$. Hydroxypyruvate reductase (HPR; EC 1.1.1.81) activity was assayed according to Kleczkowski and Edwards (1989). A reaction mixture contained $100 \mathrm{mM}$ Mes (pH 6.5), $0.2 \mathrm{mM} \mathrm{NAD(P)H}$, and $1 \mathrm{mM}$ hydroxypyruvate.

Chlorophyll content was determined according to Torrecillas et al. (1984). The extraction was realised with acetone $80 \%$ and the absorbance was measured at 649 and $665 \mathrm{~nm}$. Protein content was estimated according to Bradford (1976).

Statistical analysis: Results were expressed as means \pm standard errors. All analyses were carried out with GraphPad Prism 6.0 for Windows (GraphPad software, San Diego, CA, USA). Significant differences between treatment effects were determined by one-way ANOVA followed by the Tukey post-hoc test for multiple comparisons.

\section{Results}

Cakile maritima requires $100 \mathrm{mM} \mathrm{NaCl}$ (Fig. 1A) to express its maximal growth rate (125\% of control). Plants exposed to $200 \mathrm{mM} \mathrm{NaCl}$ have shown a growth reduction of $13 \%$ compared to control plants. However, no symptoms of leaf necrosis were shown (Fig. 1B).

The purity of isolated peroxisomes and mitochondria is illustrated in Tables 1 and 2 . In mitochondria, on the basis of the specific activity of HPR and CAT, there was contamination of around $8.5 \%$ with peroxisomes. Similarly, the mitochondrial contamination of peroxisomes estimated from the fumarase and cytochrome $c$ oxidase activities was around 13 and $20 \%$, respectively. Glucose-6P dehydrogenase activity and chlorophyll content did not exceed $5 \%$ in the two purified organelles.

Protein carbonyl content and lipid peroxidation (Fig. 2A,B) in mitochondria remained virtually independent of $\mathrm{NaCl}$ concentration. On the contrary, in peroxisomes, protein carbonyl content as well as malondialdehyde (MDA) content decreased by 20 and $30 \%$, respectively, at $100 \mathrm{mM} \mathrm{NaCl}$ in comparison to control plants. However, a slight increase of $5 \%$ in protein carbonyl content and a decrease of $10 \%$ in MDA content were observed at $200 \mathrm{mM} \mathrm{NaCl}$, respectively. The content of $\mathrm{H}_{2} \mathrm{O}_{2}$ and $\mathrm{O}_{2}^{--}$(Fig. 2C,D) increased with $\mathrm{NaCl}$ concentration in mitochondria, but in peroxisomes, these ROS did not present a significant variation with salinity.

Activity of CAT (Fig. 3A) was much higher in peroxisomes than in mitochondria independently of salinity (12 times higher at $100 \mathrm{mM} \mathrm{NaCl}$ and 4 times higher at $200 \mathrm{mM} \mathrm{NaCl}$ in comparison to the mitochondria fraction). It revealed a maximum activity at $100 \mathrm{mM} \mathrm{NaCl}$. In both mitochondrion fraction and peroxisome fraction, CAT activities were higher under salinity than in control plants.

Independently of salinity, SOD activity (Fig. 3B) was higher in peroxisomes than in mitochondria. In peroxisomes, SOD activity increased by 60 and $75 \%$, respectively, in plants treated with 100 and $200 \mathrm{mM} \mathrm{NaCl}$ compared to control plants. However, in the mitochondria fraction, SOD activity increased only by $40 \%$ under 100 and $200 \mathrm{mM} \mathrm{NaCl}$.
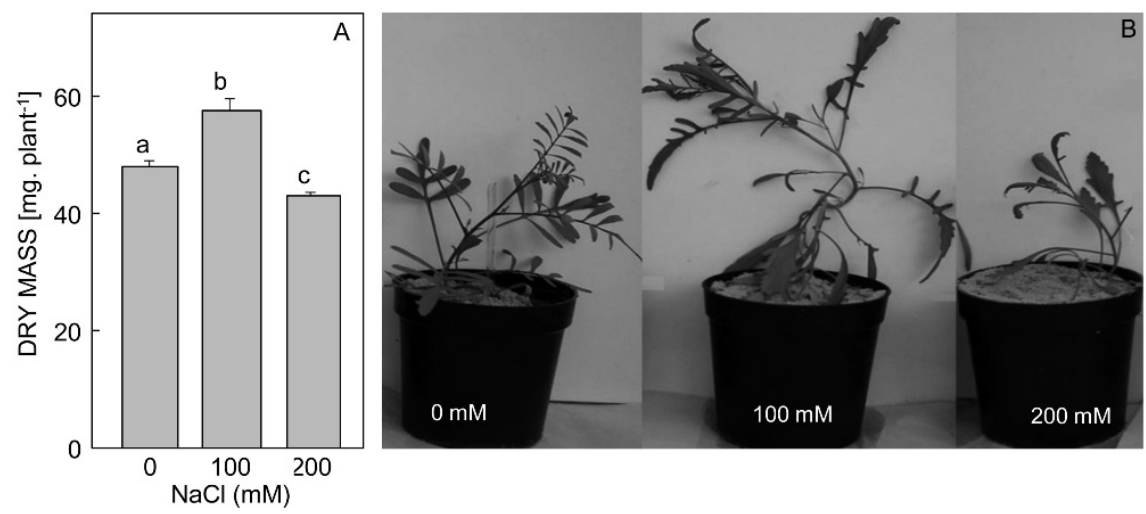

Fig. 1. Effects of $\mathrm{NaCl}$ on dry mass $(A)$ and morphology $(B)$ of five-week-old Cakile maritima. Means $\pm \mathrm{SE}, n=10$, different letters indicate significant differences at $P<0.05$ between treated and control plants. 


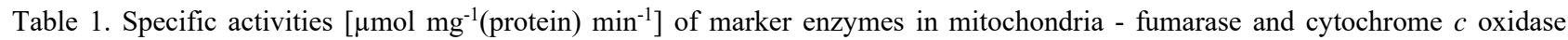
(CCO) and in peroxisomes - hydroxypyruvate reductase (HPR) and catalase (CAT) from five-week-old Cakile maritima. Means \pm SEs, $n=10$, percentage of total activity.

\begin{tabular}{|c|c|c|c|c|c|c|c|c|}
\hline Organelles & $\begin{array}{l}\text { Fumarase } \\
\text { activity }\end{array}$ & $\%$ & $\begin{array}{l}\mathrm{CCO} \\
\text { activity }\end{array}$ & $\%$ & $\begin{array}{l}\text { HPR } \\
\text { activity }\end{array}$ & $\%$ & $\begin{array}{l}\text { CAT } \\
\text { activity }\end{array}$ & $\%$ \\
\hline Mitochondria & $1.67 \pm 0.016$ & 87.4 & $2.81 \pm 0.047$ & 80 & $0.63 \pm 0.04$ & 8.3 & $0.29 \pm 0.03$ & 8.5 \\
\hline Peroxisomes & $0.24 \pm 0.048$ & 12.6 & $0.70 \pm 0.096$ & 20 & $7.00 \pm \pm 0.32$ & 91.7 & $3.10 \pm 0.08$ & 91.5 \\
\hline
\end{tabular}

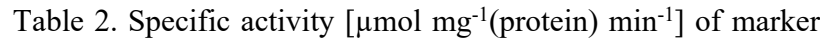
enzyme glucose-6-phosphate dehydrogenase (G6PDH) and chlorophyll content $\left[\mu \mathrm{g} \mathrm{cm}^{-3}\right]$ in crude extracts from five- weekold Cakile maritima. Means \pm SEs, $n=10$, percentage of total content or activity.

\begin{tabular}{|c|c|c|c|c|}
\hline Organelles & $\begin{array}{l}\text { Chlorophyll } \\
\text { content }\end{array}$ & $\%$ & $\begin{array}{l}\text { G6PDH } \\
\text { activity }\end{array}$ & $\%$ \\
\hline Mitochondria & $0.04 \pm 0.001$ & 4.3 & $0.09 \pm 0.001$ & 3.6 \\
\hline Peroxisomes & $0.039 \pm 0.007$ & 4.2 & $0.11 \pm 0.005$ & 4.4 \\
\hline Chloroplasts & $0.840 \pm 0.040$ & 91.5 & $2.30 \pm 0.016$ & 9.0 \\
\hline
\end{tabular}

Activity of POD (Fig. 3C) was almost the same in different organelles of control plants. However, the impact of salinity was much more pronounced in the mitochondria fraction. In fact, POD activity increased 4 times at $100 \mathrm{mM} \mathrm{NaCl}$ and 6.5 times at $200 \mathrm{mM} \mathrm{NaCl}$ in comparison to control plants. In peroxisomes, POD activity increased only slightly under the salinity.

Activity of APX (Fig. 4A) was 2.5 times higher in peroxisomes than in mitochondria independently of salinity. It increased by $20 \%$ in plants treated with $100 \mathrm{mM} \mathrm{NaCl}$ and decreased by $5 \%$ under $200 \mathrm{mM}$ $\mathrm{NaCl}$ in comparison to control plants. However, APX activity in mitochondria was rather low and independent on salinity.

Under different $\mathrm{NaCl}$ concentrations, GR activity (Fig. 4B) was more important in peroxisomes than in mitochondria. Generally, GR activity, increased by $10 \%$ at the moderate salinity and decreased by $4 \%$ at the high salinity in both the organelles. Similarly, MDHAR and DHAR activities (Fig. 4C,D) were higher in peroxisomes than in mitochondria. These activities changed insignificantly under salinity with exception of a slight increase in peroxisomes under $1 \mathrm{mM} \mathrm{NaCl}$.

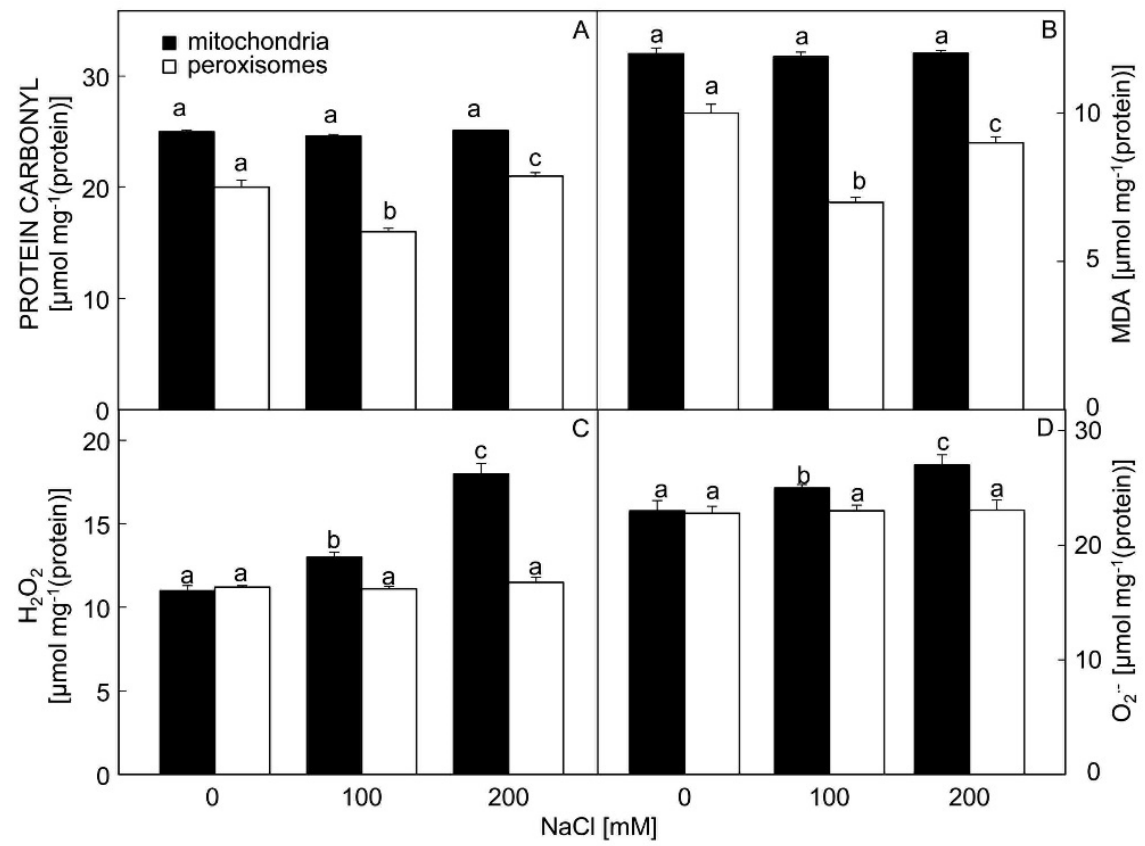

Fig. 2. Effects of $\mathrm{NaCl}$ on protein carbonyl content $(A)$, malonyldialdehyde (MDA) content $(B)$, hydrogen peroxide content $(C)$, and superoxide radical content $(D)$ in mitochondria and peroxisomes of five-wee-old Cakile maritima. Means \pm SEs, $n=3$, different letters indicate significant differences at $P<0.05$ between treated and control plants. 


\section{Discussion}

Cakile maritima is considered to be a halophyte plant, and in fact, its maximum growth was observed under a moderate salinity. The relative salt tolerance of Cakile maritima has been described to be associated with an efficient antioxidant system including glutathione content together with a low MDA content, electrolyte leakage, and $\mathrm{H}_{2} \mathrm{O}_{2}$ content (Ben Amor et al. 2006, 2010). Differences in antioxidant enzymes and non-enzymatic antioxidants between individual cell organelles in glycophytes, such as Pisum sativum, (Jiménez et al. 1997, 1998, Gómez et al. 2003), Solanum lycopersicum (Kuzniak and Skłodowska 2005), and Arabidopsis thaliana (Rodríguez-Serrano 2009), have been previously reported. However, to our knowledge, there is no information concerning the implication of the organelles in the antioxidant defense as well as the tolerance to salinity in Cakile maritima. The question posed here is how halophytes in general and Cakile maritima specifically, control the rate of ROS production and ROS scavenging when they are exposed to salinity. Our results reveal that in Cakile maritima, mitochondria and peroxisomes behaved differently under salinity. These differences appeared at two levels: oxidative stress parameters and antioxidant enzymes. Our results indicate that salinity induced a more severe oxidative stress in mitochondria than in peroxisomes where MDA and $\mathrm{CO}^{-}$ proteins content remained generally unchanged.

In the present study, two hypotheses were suggested. The first hypothesis considers that the majority of ROS are essentially produced in mitochondria and not in peroxisomes under salt stress. Consequently, the antioxidant enzymes might be unable to ensure ROS detoxification in mitochondria. The second hypothesis considers that the production of ROS under salt stress occurred not only in mitochondria but also in peroxisomes. Nevertheless, the efficient antioxidant defense is in the peroxisomes. Our results show an important content of $\mathrm{H}_{2} \mathrm{O}_{2}$ and $\mathrm{O}_{2}^{-}$in both peroxisomes and mitochondria, which excludes the first hypothesis. However, $\mathrm{H}_{2} \mathrm{O}_{2}$ and $\mathrm{O}_{2}^{-}$content increased with the increased salinity in mitochondria but not in peroxisomes. These results are in agreement with those of Mittova et al. (2004) who showed that the increase of oxidative stress was detected essentially in mitochondria and not in peroxisomes. This suggests the presence of efficient antioxidant enzymes in peroxisomes.

The SOD is one of the most important enzymes of the plant defense system (Del Río et al. 1992). Our study has revealed that at moderate and high salinities, the dismutation of superoxide by SOD was realized essentially in peroxisomes. It has been suggested previously, that peroxisomes are organelles with the capacity to generate and release $\mathrm{O}_{2}{ }^{--}$and $\mathrm{H}_{2} \mathrm{O}_{2}$ into the cytosol, which can contribute to communication among cell compartments (Del Río et al. 2006, Gill and Tuteja
2010, Corpas et al. 2015). Further, an increase in pea mitochondrial Mn-SOD with salinity was found by Gómez et al. (1999) and a correlation between salt tolerance and increased Mn-SOD activity in tomato, wheat, and pea (Hernández et al. 1993, Sairam and Srivastava 2002, Mittova et al. 2003). However, a discrepancy exists for the peroxisomal Mn-SOD isoform since it is not induced under salinity in pea tolerant or sensitive cultivars (Corpas et al. 1993b).

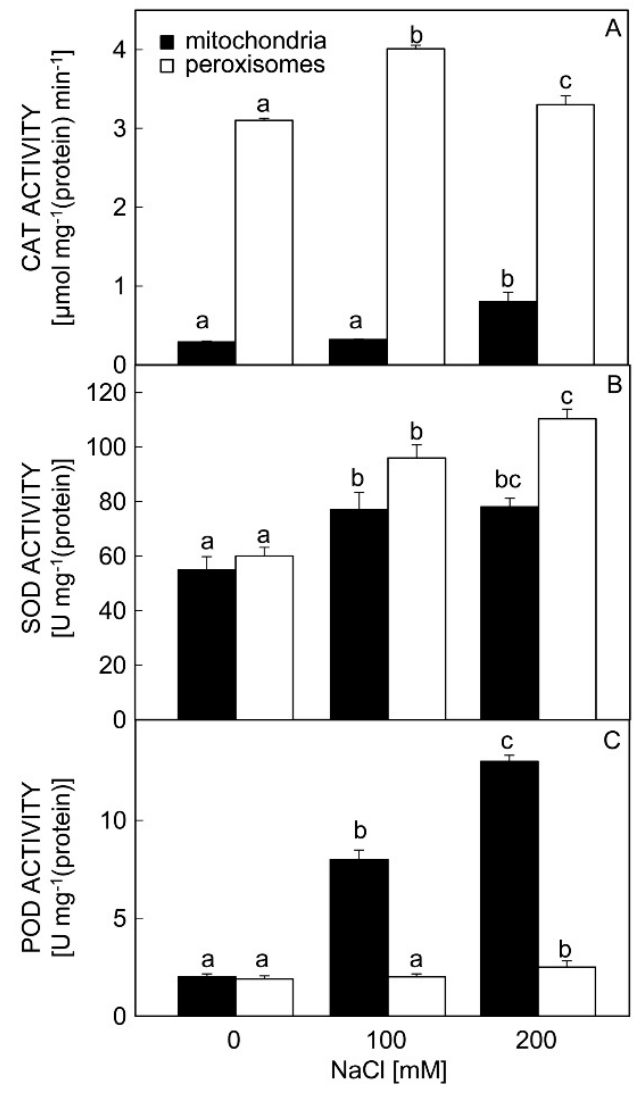

Fig. 3. Changes in catalase (CAT) $(A)$, superoxide dismutase (SOD) $(B)$, and peroxidase (POD) $(C)$ activities in mitochondria and peroxisomes from five-week-old Cakile maritima in response to $\mathrm{NaCl}$. Means $\pm \mathrm{SEs}, n=3$, different letters indicate significant differences at $P<0.05$ between treated and control plants.

The $\mathrm{H}_{2} \mathrm{O}_{2}$ formed after dismutation of $\mathrm{O}_{2}^{--}$in peroxisomes of Cakile maritima under salt stress was rapidly eliminated by several antioxidant enzymes. However, in mitochondria, $\mathrm{H}_{2} \mathrm{O}_{2}$ content remained high under the salinity, which implicates a less efficient antioxidant system in this organelle. The $\mathrm{H}_{2} \mathrm{O}_{2}$ produced in peroxisomes is mostly decomposed by CAT isoenzymes localized in the matrix usually in the form of organized structures called crystalline cores (Igamberdiev and Lea 2002). The present study has shown an important activity of CAT in peroxisomes essentially at the 
moderate $\mathrm{NaCl}$ concentration suggesting a key role for this enzyme in Cakile maritima salt tolerance. However, a decline in CAT activity was described in pea peroxisomes under salinity (Corpas et al. 1993b). On the other hand, in a previous study (Ben Amor et al. 2006), we showed a decline in CAT activity under salinity in the leaves of Cakile maritima. These data indicate that apart from CAT, the presence of other antioxidant enzymes localized in peroxisomes is probably involved in the elimination of $\mathrm{H}_{2} \mathrm{O}_{2}$. There are several experimental evidences for the existence of the ascorbate-glutathione cycle in peroxisomes (Jiménez et al. 1997, Mittova et al. 2000, Del Rio et al. 2002, Ashraf 2009, Hu et al. 2012). Our results indicate that APX, MDHAR, DHAR, and GR played a crucial roles in the elimination of oxidative stress and therefore in the tolerance of Cakile maritima especially under salt stress. These enzymes presented mostly higher activities at $100 \mathrm{mM} \mathrm{NaCl}$ than at 0 and
$200 \mathrm{mM} \mathrm{NaCl}$ which is similar to results previously described by Gómez et al. (1999) for pea mitochondria. However, these activities were higher in peroxisome than in mitochondria in different salt concentrations. This suggests the essential role of peroxisomes for salt tolerance of this halophyte. It is worthy to note that scavenging $\mathrm{H}_{2} \mathrm{O}_{2}$ is carried out not only by CAT but also by the ascorbate glutathione cycle. On the other hand, several studies showed the implication of chloroplasts in the detoxification of ROS (Asada 1999, Foyer and Noctor 2003). There is a possibility that chloroplasts of Cakile maritima could also play a role in the elimination of ROS and in the tolerance to salinity.

The current study has shown the important role of peroxisomes for the antioxidant defense against oxidative stress and consequently their implication on the tolerance of Cakile maritima under salt stress.

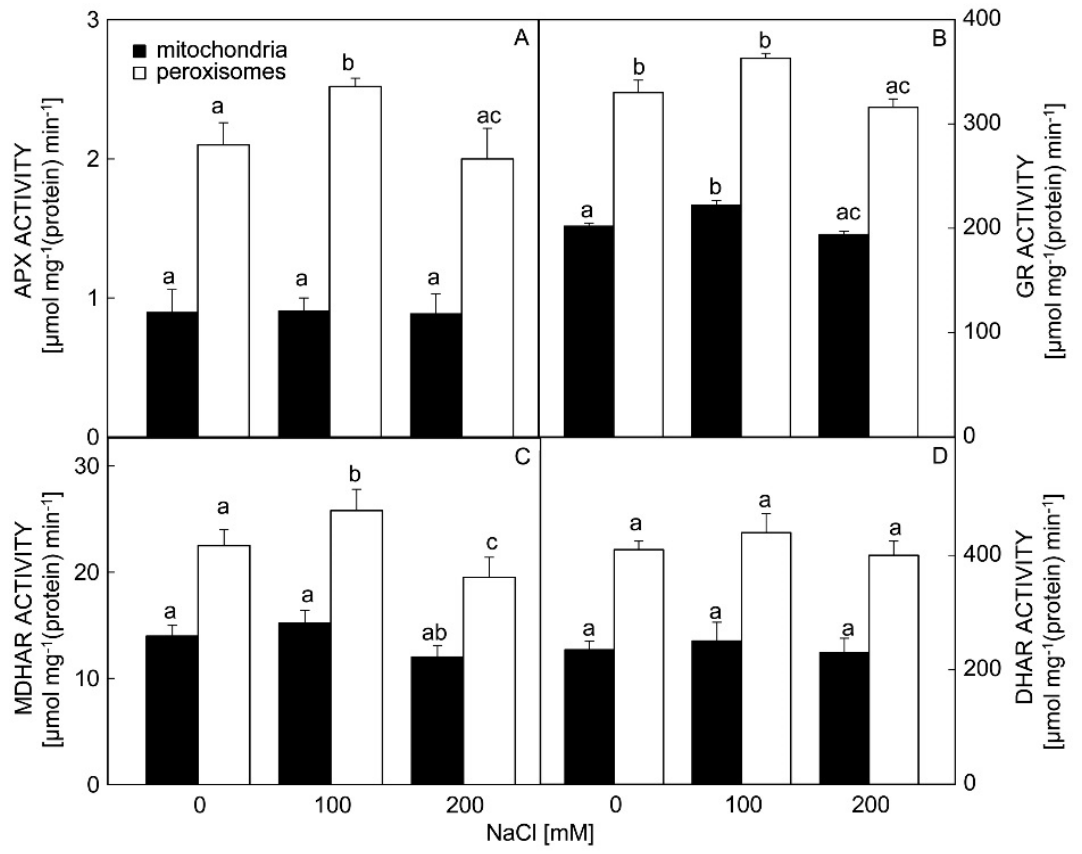

Fig. 4. Changes in activities of ascorbate peroxidase (APX) (A), glutathione reductase (GR) (B), monodehydroascorbate reductase (MDHAR) $(C)$, and dehydroascorbate reductase (DHAR) $(D)$ in mitochondria and peroxisomes from five-week-old Cakile maritima in response to $\mathrm{NaCl}$. Means $\pm \mathrm{SEs}, n=3$, different letters indicate significant differences at $\mathrm{P}<0.05$ between treated and control plants.

\section{References}

Aebi, H.: Catalase in vitro. - Methods Enzymol. 105: 121-126, 1984.

Apel, K., Hirt, H.: Reactive oxygen species: metabolism, oxidative stress, and signal transduction. - Annu. Rev. Plant Biol. 55: 373-399, 2004.

Arrigoni, O., Dipierro, S., Borraccino, G.: Ascorbate free radical reductase: a key enzyme of the ascorbic acid system. - FEBS Lett. 125: 242-244, 1981.

Asada, K.: The water-water cycle in chloroplasts: scavenging of active oxygen and dissipation of excess photons. - Annu.
Rev. Plant Physiol. Plant mol. Biol. 50: 601-639, 1999.

Asada, K.: The water-water cycle as alternative photon and electron sinks. Philosophical Transactions of the Royal Society of London, Series B. Biological Sciences. 355: 1419-1431, 2000.

Ashraf, M.: Biotechnological approach of improving plant salt tolerance using antioxidants as markers. - Biotech. Adv. 27: 84-93, 2009.

Ben Amor, N., Ben Hamed, K., Debez, A., Grignon, G., Abdelly, C.: Physiological and antioxidant responses of the 
perennial halophyte Crithmum maritimum to salinity.- Plant Sci. 168: 889-899, 2005.

Ben Amor, N., Jiménez, A., Megdiche, W., Lundqvist, M., Sevilla, F., Abdelly, C.: Response of antioxidant systems to $\mathrm{NaCl}$ stress in the halophyte Cakile maritima. - Physiol. Plant. 126: 446-457, 2006.

Ben Amor, N., Megdiche, W., Jiménez, A., Sevilla, F., Abdelly, C.: The effect of calcium on the antioxidant systems in the halophyte Cakile maritima under salt stress. - Acta Physiol. Plant. 32: 453-461, 2010.

Bergmeyer, H.U., Gawwehn, K., Grassl, M.: Enzymes as biochemical reagents. - In Bergmeyer, H.U. (ed.): Methods of Enzymatic Analysis. Pp. 425-556. Academic Press, New York 1974.

Boveris, A.: Determination of the production of superoxide radicals and hydrogen peroxide in mitochondria. -Methods Enzymol. 105: 429-435, 1984.

Bradford, M.M.: A rapid and sensitive method for the quantitation of microgram quantities of protein utilizing the principle of protein dye binding. - Anal. Biochem. 72: 248254, 1976.

Buege, A.J., Aust, S.D.: Microsomal lipid peroxidation. Method Enzymol. 52: 302-310, 1972.

Corpas, F.J.: What is the role of hydrogen peroxide in plant peroxisomes?. - Plant Biol. 17: 1099-1103, 2015.

Corpas, F.J., Gomez, M., Hernández, J.A., Del Río, L.A.: Metabolism of activated oxygen in peroxisomes from two Pisum sativum $L$. cultivars with different sensitivity to sodium chloride. - J. Plant Physiol. 89: 103-110, 1993 b.

Corpas, F.J., Palma, J.M., Del Río, L.A.: Evidence for the presence of proteolytic activity in peroxisomes. - Eur. J. cell. Biol. 61: 81-85, 1993a.

Dalton, D.A., Baird, L.M., Langeberg, L., Taugher, C.Y., Anyan, W.R., Vance, C.P., Sarath, G.: Subcellular localization of oxygen defense enzymes in soybean (Glycine max [L.] Merr.) root nodules. - Plant Physiol. 102: 481-489, 1993.

Debez, A., Ben Hamed, K., Grignon, C., Abdelly, C.: Salinity effects on germination, growth, and seed production of the halophyte Cakile maritima. - Plant Soil 262: 179-189, 2004.

Debez, A., Braun, H., Pich, A, Taamalli, W., Koyro, H., Abdelly, C., Huchzermeyer, B.: Proteomic and physiological responses of the halophyte Cakile maritima to moderate salinity at the germinative and vegetative stages. J. Proteomics 75: 5667-5694, 2012.

Del Río, L.A., Corpas, F.J., Sandalio, L.M., Palma, J.M., Gómez, M., Barroso, J.B.: Reactive oxygen species, antioxidant systems and nitric oxide in peroxisomes - J. exp. Bot. 53: 1255-1272, 2002.

Del Río, L.A., Sandalio, L.M., Corpas, F.J., Palma, J.M., Barroso, J.B.: Reactive oxygen species and reactive nitrogen species in peroxisomes. Production, scavenging, and role in cell signaling. - Plant Physiol. 141: 330-335, 2006.

Del Río, L.A., Sandalio, L.M., Palma, J.M., Bueno, P., Corpas, F.J.: Metabolism of oxygen radicals in peroxisomes and cellular implications. - Free Radical Biol. Med. 13: 557$580,1992$.

Demidchik, V.: Mechanisms of oxidative stress in plants: from classical chemistry to cell biology. - Environ. exp. Bot. 109: 212-228, 2015

Doehlert, D.C., Kuo, T.M., Felker, F.C.: Enzymes of sucrose and hexose metabolism in developing kernels of two inbreeds of maize. - Plant Physiol. 81: 511-515, 1988

Edwards, E.A., Rawsthorne, S., Mullineaux, P.M.: Subcellular distribution of multiple forms of glutathione reductase in leaves of pea (Pisum sativum L.). - Planta. 180: 278-284, 1990.

Foyer, C.H., Lopez-Delgado, H., Dat, J.E., Scott, I.M.: Hydrogen peroxide- and glutathione-associated mechanisms of acclamatory stress tolerance and signalling. - Physiol. Plant. 100: 241-254, 1997.

Foyer, C.H., Noctor, G.: Redox sensing and signaling associated with reactive oxygen in chloroplasts, peroxisomes and mitochondria. - Physiol. Plant. 119: 355364,2003

Frew, J., Jones, P., Scholes, G.: Spectrophotometric determination of hydrogen peroxide and organic hydroperoxides at low concentrations in aqueous solution. Anal. chim. Acta 155: 130-150, 1983.

Gill, S.S., Tuteja, N.: Reactive oxygen species and antioxidant machinery in abiotic stress tolerance in crop plants. - Plant Physiol. Biochem. 48: 909-930, 2010.

Gomez, J.M., Hernández, J.A., Jimènez, A., Del Río, L.A., Sevilla, F.: Differential response of antioxidative enzymes of chloroplasts and mitochnodria to long-term $\mathrm{NaCl}$ stress of Pea plants. - Free Rad. Res. 31: 11-18, 1999.

Gomez, S.M., Kalamani, A.: Butterfly Pea (Clitoria ternatea): A nutritive multipurpose forage legume for the tropics - An overview. - Pakistan J. Nutrition. 2: 374-379. 2003.

Hernández, J.A., Corpas, F.J., Gómez, M., Del Río L.A., Sevilla, F.: Salt induced oxidative stress mediated by activated oxygen species in pea leaf mitochondria. Physiol. Plant. 89: 103-108, 1993.

Hewitt, E.J.: Sand and Water Culture Methods Used in the Study of Plant Nutrition. - Commonwealth Bureau of Horticulture, East Malling 1966.

Igamberdiev, A.U., Lea, P.J.: The role of peroxisomes in the integration of metabolism and evolutionary diversity of photosynthetic organisms. - Biochemistry 60: 651-674, 2002.

Hu, J., Baker, A., Bartel, B., Linka, N., Mullen, R.T., Reumann, S., Zolman, B.K.: Plant Peroxisomes: Biogenesis and Function. - Plant Cell. 24: 2279-2303, 2012.

Jimènez, A., Hernandez, J.A., Del Rio, L., Sevilla, F.: Role of the ascorbate-glutathione cycle of mitochondria and peroxisomes in the senescence of pea leaves. - Plant Physiol. 118: 1327-1335, 1998.

Jimènez, A., Hernandez, J.A., Del Río, L.A., Sevilla, F.: Evidence for the presence of the ascorbate-glutathione cycle in mitochondria and peroxisomes of pea leaves. - Plant Physiol. 114: 275-284, 1997.

Jithesh, M.N., Prashanth, S.R., Sivaprakash, K.R., Ajay, K., Parida, A.K.: Antioxidative response mechanisms in halophytes: their role in stress defence. - J. Genet. 85: 237 254. 2006.

Karkonen, A., Kuchitsu, K.: Reactive oxygen species in cell wall metabolism and development in plants. Phytochemistry 112: 22-32. 2015.

Kleczkowski, A., Edwards, E.: Identification of hydroxypyruvate and glyoxylate reductases in maize leaves. - Plant Physiol. 91: 278-286. 1989.

Kuzniak, E., Skłodowska, M.: Fungal pathogen-induced changes in the antioxidant systems of leaf peroxisomes from infected tomato plants. - Planta. 222: 192-200, 2005.

Levine, R.L., Garland, D., Oliver, C.N., Amici, A., Climent, I., 
Lens, A.G., Ahn, B.W., Shaltiel, S., Stadtman, E.R.: Determination of carbonyl content in oxidatively modified proteins. - Methods Enzymol. 186: 464-478, 1990.

Lokhande, V.H., Suprasanna, P.: Prospects of halophytes in understanding and managing abiotic stress tolerance. - In: Ahmad, P. (ed.: Environal Adaptations and Stress Tolerance of Plants in the Era of Climate Change. Pp. 29-56. Springer, Berlin 2012.

McCord, J.M., Fridovich, I.: Superoxide dismutase: an enzymatic function for erythrocuprein. - Int. J. Biochem. cell. Biol. 244: 6049-6055, 1969.

Mittler, R.: Oxidative stress, antioxidants and stress tolerance. Trends Plant Sci. 7: 405-410, 2002.

Mittova, V., Tal, M., Volokita, M., Guy, M.: Up-regulation of the leaf mitochondrial and peroxisomal antioxidative systems in response to salt-induced oxidative stress in the wild salt-tolerant tomato species Lycopersicon pennellii. Plant Cell. Environ. 26: 845-856, 2003.

Mittova, V., Volokita, M., Guy, M., Tal, M.: Activities of SOD and the ascorbate-glutathione cycle enzymes in subcellular compartments in leaves and roots of the cultivated tomato and its wild salt tolerant relative Lycopersicon pennellii. Physiol. Plant. 110: 42-51, 2000.

Mittova, V., Volokita, M., Guy, M., Tal, M., Volokita, M.: Salinity up-regulates the antioxidative system in root mitochondria and peroxisomes of the wild salt-tolerant tomato species Lycopersicon pennellii. - J. exp. Bot. 55: 1105-1113, 2004.

Moller, I.M.: Plant mitochondria and oxidative stress electron transport, nadph turnover, and metabolism of reactive oxygen species. - Annu. Rev. Plant Physiol. Plant mol. Biol. 52: 561-591, 2001.

Ranieri, A., Petacco, F., Castagna, A., Soldatini, G.F.: Redox state and peroxidase system in sunflower plants exposed to ozone. - Plant Sci. 159: 159-168, 2000.

Rodriguez-Serrano, M., Romero-Puertas, M.C., Pazmino, D.M., Testillano, P.S., Risueno, M.C., Del Río L.A., Sandalio, L.M.: Cellular response of pea plants to cadmium toxicity: cross talk between reactive oxygen species, nitric oxide, and calcium. - Plant Physiol. 150: 229-243, 2009.

Sairam, R.K., Srivastava, G.C.: Changes in antioxidant activity in sub-cellular fractions of tolerant and susceptible wheat genotypes in response to long-term salt stress. - Plant Sci. 162: 897-904, 2002.

Serrano, R., Mulet, J.M., Rios, G., Marquez, J.A., De Larrinoa, I.F., Leube, M.P., Iratxe, M., Amparo, P.A., Markus, P., Roc, R., Consuelo, M.: A glimpse of the mechanisms of ion homeostasis during salt stress. - J. exp. Bot. 50: 1023-1036, 1999.

Sevilla, F., Jimènez, A., Lazaro, J.J.: What do the plant mitochondrial antioxidant and redox systems have to say under salinity, drought, and extreme temperature? - In: Gupta, D.K., Palma, J.M., Corpos, F.J. (ed.): Reactive Oxygen Species and Oxidative Damage in Plants Under Stress. Pp. 23-55. Springer, Dordrecht 2015.

Smirnoff, N.: The role of active oxygen in the response of plants to water deficit and desiccation. - New Phytol. 125: 27-58, 1993.

Torrecillas, A., Léon, A., Del Amor, F., Martinez-Mompean, M.C.: Rapid determination of chlorophyll. - Fruits 39: 617622, 1984.

Zarrouk, M., El Almi, H., Ben Youssef, N., Sleimi, N., Smaoui, A., Ben Miled, D.: Lipid composition of local halophytes seeds: Cakile maritima, Zygophyllum album and Crithmum maritimum. - In: Lieth, H, (ed.): Cash Crop Halophytes: Recent Studies. Pp. 121-126. Kluwer Academic Publishers, Dordrecht 2003. 